\title{
Mortality from Ischaemic Heart Disease in the Armed Forces 1973-1984
}

Miss J. Gray,

CBSCS at Med Stats, $1985 / 86$

SUMMARY: This study investigates mortality from ischaemic heart disease during 1973-1984 in males under 55 years of age in the three Armed Services. Comparisons are drawn within and between each service and with ischaemic heart disease (IHD) mortality in the UK male population.

Evidence of a significant decline in the Army death rate over this 12 year period has been found. Officers in each Service are seen to have a much higher rate of mortality, ie death rate per 100,000 at risk, than other ranks but a much lower rate when age distribution relative to the UK population is taken into account as indicated by the Standardised Mortality Ratios. The Army other ranks in the 25-39 age range are identified as a particularly high risk group for IHD.

The wide ranging effects of social habits and the peculiarities of military life style may go part way to explaining the diversity between officers and other ranks and between the services and the general UK male population.

\section{Introduction}

The number of malc deaths from ischaemic heart disease (IHD) in the three Armed Services is of major concern. This study looks at mortality in each Service during 1973-1984, drawing comparisons between individual Services, and between the Services and the UK male population.

\section{Data}

The study covers all Regular serving males (excluding Gurkhas) who died from IHD (coded 410-414 in the eighth and ninth editions of the International Classification of Diseases) during 1973-1984. The information was obtained from the Tri-Service Medical Statistics Branch of the Ministry of Defence. The cause of death was confirmed by post mortem records in $75 \%$ of the cases.

The population of personnel aged over 54 in each Service is small, making meaningful analysis of the deaths in this age group difficult. In view of this, the nine Army and four RAF cases have been excluded from the analyses.

The UK male population data were obtained from the Office of Population Censuses and Surveys, the General Register Office of Scotland and the Registrar General of Northern Ireland.

\section{Results}

In the 12 year period there were 605 male deaths in all three Services from IHD, and a further 41 deaths where IHD was implicated as a secondary cause of death.

The figures in Table 1 summarise all male deaths in the Services over the period. IHD can be seen to account for approximately one third of all the disease deaths in each Service.

Table 2 summarises the IHD deaths by Service anc year for all ranks, officers and other ranks separately $\mathbb{Q}$ The inclusion of the death rate per 100,000 strengt! provides a broad comparison of the incidence of death within and between the Services, but it does not allow for differences in the age distributions.

The Spearman rank correlation coefficient tren analysis technique was used to test the hypothesis that there is evidence of a favourable (decreasing) trend in the death rates over time. The results are given in Table 3. All nine results indicate evidence of a favourable trend. High negative values indicate a very strong trend and low negative values indicate a weak trend. Of the three Services the Army can be seen to have the strongest evidence of a decline in the death rate over time, particularly evident amongst the officers and all ranks groupings.

Table 1

Summary of Male Mortality all ages(a) 1973-1984 
Table 2

Mortality rates for IHD per 100,000 male strength at risk in each Service aged under 55 for 1973-1984

\begin{tabular}{|c|c|c|c|c|c|c|}
\hline & $\begin{array}{c}\text { All Ranks } \\
\text { IHD } \\
\text { Deaths }\end{array}$ & $\begin{array}{l}\text { Death Rate } \\
\text { per } 100,000\end{array}$ & $\begin{array}{c}\text { Officers } \\
\text { IHD } \\
\text { Deaths }\end{array}$ & $\begin{array}{l}\text { Death Rate } \\
\text { per } 100,000\end{array}$ & $\begin{array}{c}\text { Other Ranks } \\
\text { IHD } \\
\text { Deaths }\end{array}$ & $\begin{array}{l}\text { Death Rate } \\
\text { per } 100,000\end{array}$ \\
\hline \multicolumn{7}{|l|}{ NAVY } \\
\hline 1973 & 9 & 11.6 & 3 & 29.6 & 6 & 8.9 \\
\hline 1974 & 9 & 12.1 & 2 & 19.9 & 7 & 10.9 \\
\hline 1975 & 10 & 13.9 & 3 & 30.3 & 7 & 11.2 \\
\hline 1976 & 7 & 9.7 & 1 & 10.2 & 6 & 9.6 \\
\hline 1977 & 9 & 12.5 & 4 & 41.3 & 5 & 8.1 \\
\hline 1978 & 3 & 4.3 & 0 & 0.0 & 3 & 4.9 \\
\hline 1979 & 5 & 7.3 & 3 & 31.6 & 2 & 3.4 \\
\hline 1980 & 7 & 10.3 & 3 & 31.1 & 4 & 6.8 \\
\hline 1981 & 7 & 10.0 & 1 & 10.1 & 6 & 10.0 \\
\hline 1982 & 4 & 5.9 & 2 & 20.5 & 2 & 3.4 \\
\hline 1983 & 10 & 14.8 & 1 & 10.6 & 9 & 15.5 \\
\hline 1984 & 6 & 9.0 & 1 & 10.7 & 5 & 8.7 \\
\hline TOTAL & 86 & & 24 & & 62 & \\
\hline \multicolumn{7}{|l|}{ ARMY } \\
\hline 1973 & 29 & 17.0 & 9 & 51.6 & 20 & 13.0 \\
\hline 1974 & 27 & 16.4 & 9 & 51.8 & 18 & 12.2 \\
\hline 1975 & 33 & 20.5 & 8 & 45.9 & 25 & 17.4 \\
\hline 1976 & 34 & 20.7 & 7 & 40.4 & 27 & 18.4 \\
\hline 1977 & 26 & 16.3 & 8 & 46.9 & 18 & 12.6 \\
\hline 1978 & 20 & 13.0 & 7 & 42.8 & 13 & 9.4 \\
\hline 1979 & 29 & 19.3 & 12 & 75.4 & 17 & 12.6 \\
\hline 1980 & 24 & 15.5 & 7 & 43.8 & 17 & 12.2 \\
\hline 1981 & 23 & 14.3 & 5 & 30.8 & 18 & 12.5 \\
\hline 1982 & 22 & 14.1 & 5 & 30.9 & 17 & 12.1 \\
\hline 1983 & 19 & 12.4 & 6 & 37.7 & 13 & 9.4 \\
\hline 1984 & 18 & 11.6 & 2 & 12.5 & 16 & 11.5 \\
\hline TOTAL & 304 & & 85 & & 219 & \\
\hline \multicolumn{7}{|l|}{ RAF } \\
\hline 1973 & 21 & 21.4 & 5 & 27.3 & 16 & 20.0 \\
\hline 1974 & 21 & 22.6 & 10 & 57.3 & 11 & 14.6 \\
\hline 1975 & 21 & 23.7 & 3 & 18.0 & 18 & 25.0 \\
\hline 1976 & 19 & 22.5 & 6 & 39.0 & 13 & 18.8 \\
\hline 1977 & 20 & 24.6 & 4 & 27.5 & 16 & 24.0 \\
\hline 1978 & 14 & 17.6 & 3 & 21.6 & 11 & 16.7 \\
\hline 1979 & 12 & 14.8 & 3 & 22.1 & 9 & 13.4 \\
\hline 1980 & 10 & 11.9 & 1 & 7.3 & 9 & 12.8 \\
\hline 1981 & 14 & 16.3 & 5 & 36.0 & 9 & 12.5 \\
\hline 1982 & 13 & 15.4 & 5 & 36.0 & 8 & 11.4 \\
\hline 1983 & 19 & 22.5 & 1 & 7.2 & 18 & 25.4 \\
\hline 1984 & 18 & 20.8 & 4 & 28.8 & 14 & 19.2 \\
\hline TOTAL & 202 & & 50 & & 152 & \\
\hline
\end{tabular}


Table 3

\begin{tabular}{cccc}
\hline Service & All Ranks & Officers & Other Ranks \\
\hline Navy & -0.286 & -0.230 & -0.206 \\
Army & -0.776 & -0.741 & -0.664 \\
RAF & -0.486 & -0.185 & -0.230 \\
\hline
\end{tabular}

NOTE: The values for Army Officers and all ranks were found to be significant at the $1 \%$ level and the other ranks value at the $5 \%$ level.

Figure 1 compares death rates for all ranks by Service and five year age groups. In the 30-34 and 35-39 age groups the Army death rate is approximately twice that of the Navy and RAF. All the Services can be seen to show a sharply increasing death rate with age.

Analysis of the all ranks, officers and other ranks groupings by age (see Table 4) reveals a number of similarities and differences. The vast majority of all officer deaths in each Service occurred in the 40-54 ageband. By comparison $66 \%$ of the Army other ranks deaths occurred in the 15-39 age range, more than half of which were in the 35-39 age group. In the Navy and RAF only $48 \%$ and $26 \%$ of the other ranks deaths respectively were in the 15-39 age range.
Table 4 compares the mortality from IHD in each Service with that of the UK male population on a basis adjusted to allow for differences in age distributions. The Standardised Mortality Ratio (SMR) measures the difference between the observed number of Service deaths and the expected number based on age specific UK mortality rates. An SMR of $100 \%$ equates to the UK mortality rate, whilst higher values indicate a greater than expected number of Service deaths and lower values a lower number than would be expected.

It can be seen that the overall SMR's for all ranks, i.e., for the whole 15-54 age band, are all less than 100\% for each Service. Closer examination of the deaths by age group reveals SMR's which vary considerably. Deaths in excess of the expected number occurred in the 20-24 (Navy and RAF) and 25-29 (RAF) age groups, though the number of actual deaths were small. The Army age groups between 15 and 39 stand out as having an especially high number of excess deaths.

Analysis of the deaths between officers and other ranks highlights some striking differences. With the exception of the 20-24 age group in the Army all the officer SMR's are well below $100 \%$. In the other ranks category, whilst the overall Navy and RAF mortality is below the UK rate, this is not the case in the Army Breakdown by age reveals excess deaths to have 
Table 4

Mortality from IHD for male officers and other ranks for each Service compared with the UK male civilian population 1973- 1984

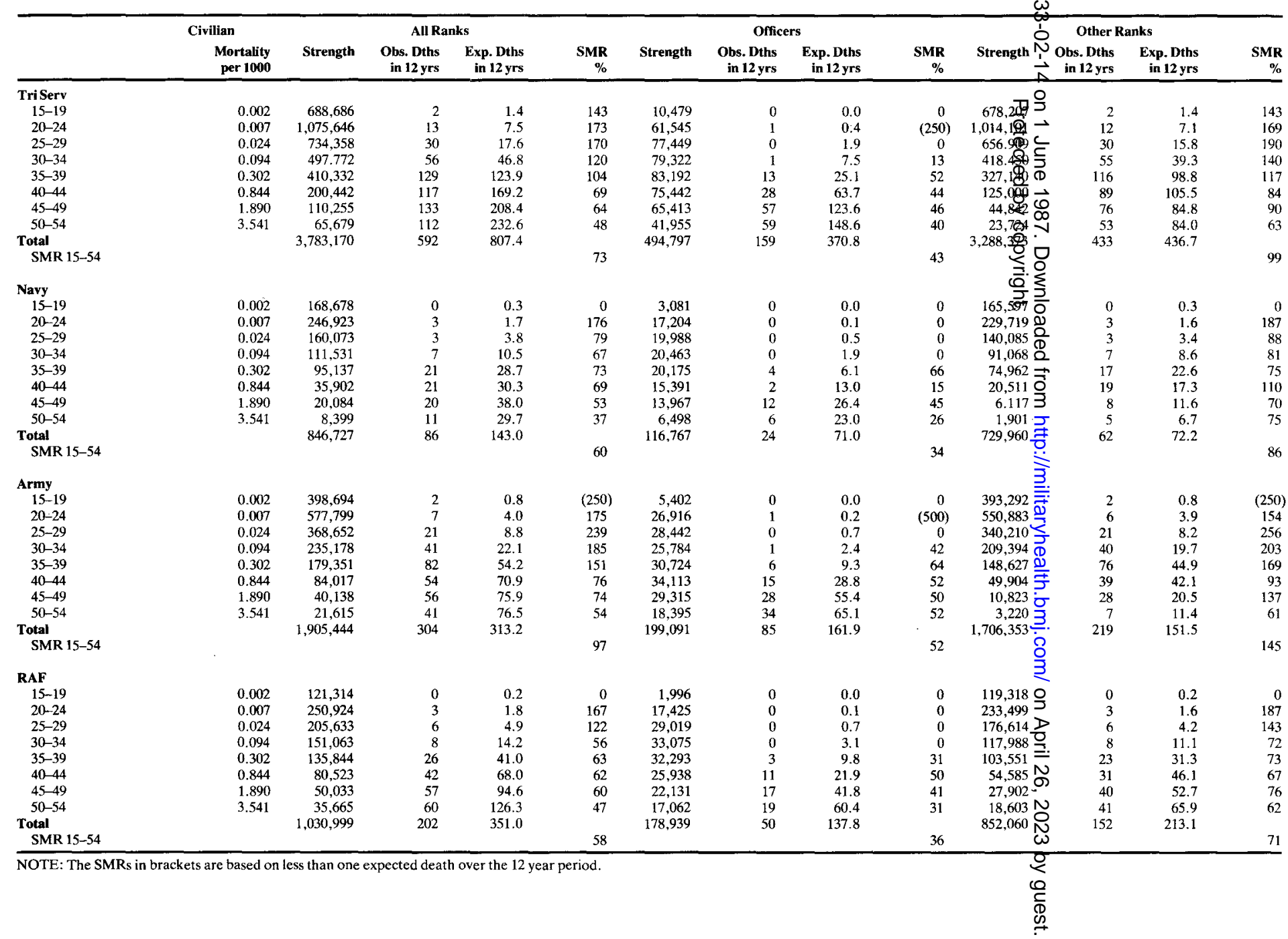


occurred in certain age groups in each Service, the greatest number being in the Army 25-29 age group where the observed number of deaths is more than $2 \frac{1}{2}$ times the expected number.

Figures for 1973-1977 were published in an earlier study on coronary heart disease $\mathrm{l}^{\mathrm{p}}$. Table 5 compares the SMR's for 1973-1977 and 1978-1984 by Service and rank. The figures for 1973-1977 have been updated in line with changes in the UK population estimates for that period, leading to only minor changes in the values of the SMR's.
(PULHEEMS) are set down as a Joint Service Policy. But are there differences in the policies of each Service in dealing with IHD?

Occupation is a source of variation between the Services. Analysis of the deaths by occupation might prove useful in highlighting specific high risk groups, to explain some of the differences not only between the Services, but between the officers and other ranks. However in practice, it has proved difficult to undertake a worthwhile analysis based on the existing data.

Figure 2 compares the geographical recruitment of

Table 5

Comparison of SMR's by Service and rank for 1973-1977 and 1978-1984

\begin{tabular}{lrrrrrr} 
& \multicolumn{2}{c}{ All Ranks } & \multicolumn{2}{c}{$\begin{array}{c}\text { Officers } \\
\text { SMRs }\end{array}$} & \multicolumn{2}{c}{ Other Ranks } \\
& $\mathbf{7 3 - 7 7}$ & $\mathbf{7 8 - 8 4}$ & $\mathbf{7 3 - 7 7}$ & $\mathbf{7 8 - 8 4}$ & $\mathbf{7 3 - 7 7}$ & $\mathbf{7 8 - 8 4}$ \\
\hline Tri-Service & 76 & 70 & 47 & 39 & 100 & 97 \\
Navy & 71 & 52 & 41 & 30 & 101 & 75 \\
Army & 101 & 93 & 55 & 50 & 149 & 140 \\
RAF & 57 & 57 & 40 & 32 & 68 & 74 \\
\hline
\end{tabular}

Examination of the SMR's indicates an improvement in Service mortality relative to the UK population between the two periods. The most significant decrease being in the Navy other ranks. The RAF other ranks is the only category for which the SMR has increased.

\section{Discussion}

The findings of the analysis raise a number of questions. Has the death rate improved because the age structure of the Service population has changed over the years, or is it due, perhaps, to a different mix of regional recruitment from high to low risk areas? Have there been improvements in screening and medical treatment? Why do the officer and other ranks SMR's of each Service differ so markedly? In particular what factors are peculiar to the Army other ranks to cause such an excessive number of deaths in the under 40's compared with the UK population? Why has the SMR for RAF other ranks increased between the two periods 19731977 and 1978-1984?

There are no simple answers to these questions. However it is possible to examine factors which may be a source of variation and thus account in part for the differences between the individual Services and between the Services and the UK population.

A previous study into heart disease $e^{1}$ has already highlighted factors associated with mortality in the Army. These included social class of recruits, medical care, cigarette smoking and diet. It is reasonable to assume that these factors will also have a bearing on the incidence of IHD in the Navy and RAF.

Medical guidelines for the screening of new recruits and for the periodic assessment of Service personnel servicemen (other ranks) by Service from each of th $\overrightarrow{0}$ UK standard regions during 1973-1984. The pattern of recruitment can be seen to be similar for each Service $\infty$ with one or two minor variations. The regional UK male IHD SMR's for the period 1973-1984 have been used to highlight those areas of a lower or higher risk of mortality from IHD. Of the total number of males recruited in each Service, $44 \%$ Navy and over $50 \%$ in the Army and RAF were recruited from high risk areas, i.e., Northern Ireland, Scotland, Wales, and the northern regions of England. By comparison only 43\% of the UK male population aged 15-34 lived in high risk areas.

Tobacco consumption, regular and excessive alcohol intake and obesity are all factors of concern in the Forces. The earlier study ${ }^{2}$ identified the very high prevalence of cigarette smoking in soldiers as a defininte risk factor for heart disease.

Although obesity and excessive alcohol consumption have not been identified as high risk factors for IHD, they may play a contributory role. Analysis of the 21 Army other ranks deaths aged 25-29 revealed the bodily condition of over $60 \%$ as being obese. Information on alcohol consumption was only available in 8 cases, of which half were considered to have a drink problem.

Tobacco, and in particular cigarette, consumption is not easily controlled. The socialising aspect of life in the Forces and the provision of cheaper alcohol and tobacco may well go to making drinking and smoking an acceptable way of life. Closer monitoring of these social habits in the Services must be given consideration. The compulsory inclusion of this information on medical records would go a long way to aiding further research. 


$$
\text { IIIIIIII }
$$


Table 6

Summary of Service invalidings from IHD aged 15-54 during 1973-1984

\begin{tabular}{lcccc}
\hline & \multicolumn{2}{c}{ Invalidings } & \multicolumn{2}{c}{ Rates per 100,000 } \\
& Officers & Other Ranks & Officers & Other Ranks \\
\hline Tri Service & 88 & 221 & 17.8 & 6.7 \\
Navy & 16 & 29 & 13.7 & 4.0 \\
Army & 17 & 65 & 9.0 & 3.8 \\
RAF & 55 & 127 & 30.7 & 14.9 \\
\hline
\end{tabular}

Physical fitness is another important aspect of Service life, perhaps under the premise that a fitter Force is a healthier Force. In 1977 the Army introduced the Basic Fitness Test as a compulsory part of training. A very recent study ${ }^{3}$ has shown that since the introduction of this test the incidence of sudden deaths in the Army has not significantly changed. There is no equivalent test in the Navy or RAF.

Stress is also a factor associated with IHD. The main characteristics of the nature of 'employment' in the Forces are markedly different from those in civilian employment. Military discipline, job security, separation from family, deployment overseas and possible involvement in hostile warfare are some of the differences which may have a bearing. where all the personnel would have died from IHD had they remained in the Service, the SMR's increase appreciably. (Table 7).

In the unlikely event of this extreme situation the officer mortality would still be well below that of the UK population but the mortality of other ranks would increase markedly, giving rise to an excess number of deaths in each Service. This still does not take into account those personnel who were invalided out for ${ }_{0}$ other medical reasons but who might have died fromo IHD if they had remained in the Services.

To endorse or refute the implications of the points mentioned, further research is needed. Ideally this should take the form of a detailed analysis of the medicak and Service history of each individual. This would theno

Table 7

Comparison of the Observed Deaths SMR's with the Observed Deaths plus Invalidings SMR's for 1973-1984

\begin{tabular}{lcccccc}
\hline & \multicolumn{3}{c}{ Observed Dths SMR's } & \multicolumn{3}{c}{ Observed Dths + Invalidings SMR's } \\
& All Ranks & Officers & Other Ranks & All Ranks & Officers & Other Ranks \\
\hline Tri-Service & 73 & 43 & 99 & 112 & 67 & 150 \\
Navy & 60 & 34 & 86 & 92 & 56 & 126 \\
Army & 97 & 52 & 145 & 123 & 63 & 187 \\
RAF & 58 & 36 & 71 & 109 & 76 & 131 \\
\hline
\end{tabular}

To what extent the factors peculiar to military life differ between each of the Services is difficult to assess. However, for example $42 \%$ of the Army's total male strength for 1973-1984 was deployed overseas compared with less than $20 \%$ in the Navy and RAF.

The process of medical discharge from the Services is an important source of bias. Table 6 summarises the invalidings from IHD over the period 1973-1984. Personnel are medically discharged in accordance with a Joint Service Policy, although the figures indicate a much higher rate of RAF invalidings.

The effect of invalidings on the Service death rates is difficult to calculate without following up each individual. However by considering the 'worst case' enable factors like length of full time Service, occupation, rank and command to be examined in more detail.

\section{REFERENCES}

1. LYNCH P and OELman B J. Mortality from coronary heart disease in the British Army compared with the civil population. BrMed J 1981; 283: 405-7.

2. LYNCH P. Coronary risk profile of young soldiers with coronary heart disease. JR Army Med Corps 1985; 131: $38-41$.

3. LYNCH $\mathrm{P}$ et al. Sudden death in sport before and after introduction of the Basic Fitness Test. I R Army Med Corps 1985; 131: 42-46. 